\title{
Estudos isotópicos das rochas granitóides neoproterozóicas da Faixa de Dobramento Paraguai
}

\author{
Antonio Misson Godoy ${ }^{1}$, Francisco Egidio Cavalcante Pinho ${ }^{2}$, Jefferson Cassu Manzano ${ }^{3}$, \\ Larissa Marques Barbosa de Araújo ${ }^{4}$, Jesué Antonio da Silva ${ }^{5}$ \& Marcos Figueiredo ${ }^{6}$
}

\begin{abstract}
Resumo A Província Granitóide Neoproterozóica do sudeste matogrossense está relacionada à evolução da Faixa de Dobramento Paraguai no limite sudeste do Cráton Amazônico e é constituída por sete corpos ígneos distintos em dois eventos magmáticos intrusivos em rochas epimetamórficas do Grupo Cuiabá. O evento magmático do sul aflora no Estado de Mato Grosso do Sul na forma de intrusões fissurais, alongadas e alinhadas na direção NNE-SSW. As idades modelo $T_{D M}$ obtidas: Taboco $(1,97 \mathrm{Ga})$, Rio Negro (1,59 Ga) e Coxim $(1,74$ $\mathrm{Ga})$ com valores de $\varepsilon_{\mathrm{Nd}}^{(0,54 \mathrm{Ga})}$ fortemente negativos $(-7,0$ a $-5,9)$. As idades de cristalizações U-Pb obtidas: Taboco $(540 \pm 4.7 \mathrm{Ma})$, Rio Negro $(547 \pm 4.9 \mathrm{Ma})$, Coxim $(540 \pm 3.6 \mathrm{Ma})$ e Sonora $(548 \pm 5.9 \mathrm{Ma})$. O evento magmático norte aflora no Estado do Mato Grosso e é formado por intrusões rapakivíticas de dimensões batolíticas dispostas segundo direção ENE-WSW. As idades modelo $T_{D M}$ obtidas: São Vicente $(1,165 \mathrm{Ga})$, Lajinha $(1,508 \mathrm{Ga})$ e Araguaiana $(1,375 \mathrm{Ga})$ com valores de $\varepsilon_{\mathrm{Nd}}{ }^{(0,50 \mathrm{Ga})}$ fortemente negativos $(-2,86 \mathrm{a}-5,87)$. As idades de cristalizações U-Pb obtidas: São Vicente $(504 \pm 8.9 \mathrm{Ma})$, Lajinha $(505,4 \pm 4.1 \mathrm{Ma})$ e Araguaiana $(509,4 \pm$ $2.2 \mathrm{Ma}$ ). Os granitóides da parte sul, mais antigos, são gerados em ambientes sin- colisional de arco continental, enquanto os do norte, mais jovens, são gerados em ambientes tardi a pós-colisional ou de descompressão durante a finalização do processo colisional. Ambos os eventos são constituídos por granitóides gerados partir de magmas de fontes distintas e independentes a partir do retrabalhamento de fragmentos crustais distintos, dominantemente ao sul, paleoproterozóicos e ao norte, mesoproterozóicos.
\end{abstract}

Palavras-chave: Rochas granitóides, geocronologia, Faixa de Dobramento Paraguai, Grupo Cuiabá.

\begin{abstract}
Isotopic studies of neoproterozoic granitic rocks from the Paraguai Folded Belt. Neoproterozoic Granitic Province of the southeast of Mato Grosso State is related to the evolutions of the Paraguai Folded Belt in the southeast border of the Amazonian Craton. It is constituted by seven igneous bodies distinct in two magmatic events intruded in epimetamorphic rocks of the Cuiabá Group. Southern magmatic event crops out in the Mato Grosso do Sul State in the shapes of fissural intrusions elongated and aligned along the NNE-SSW direction. Obtained $\mathrm{T}_{\mathrm{DM}}$ model ages: Taboco (1,97 Ga), Rio Negro (1,59 Ga) and Coxim (1,74 Ga) with strongly negative values of $\varepsilon_{\mathrm{Nd}}(0,54 \mathrm{Ga})(-7,0 \mathrm{a}-5,9)$. Obtained U-PB crystallization ages: Taboco $(540 \pm$ $4.7 \mathrm{Ma})$, Rio Negro $(547 \pm 4.9 \mathrm{Ma})$, Coxim $(540 \pm 3.6 \mathrm{Ma})$ and Sonora $(548 \pm 5.9 \mathrm{Ma})$. Northern magmatic event crops out in the Mato Grosso State and is constituted by rapakivi intrusions of batholithic dimensions disposed along the direction ENE-WSW. Obtained $\mathrm{T}_{\mathrm{DM}}$ model ages: São Vicente (1,165 Ga), Lajinha (1,508 $\mathrm{Ga})$ and Araguaiana $(1,375 \mathrm{Ga})$ with negative values of $\varepsilon_{\mathrm{Nd}}{ }^{(0,50 \mathrm{Ga})}(-2,86$ a $-5,87)$. Obtained U-PB crystallization ages: São Vicente (504 $\pm 8.9 \mathrm{Ma})$, Lajinha (505,4 $\pm 4.1 \mathrm{Ma})$ and Araguaiana (509,4 $\pm 2.2 \mathrm{Ma})$. Granitoids from southern portion are olders and were generated in a syncollisional continental arc environment while the younger bodies from the northern raised in tardi- to post-collisional or decompression environments during the end of the collisional process. Both the events are constituted by granitic rocks generated from magmas from different and independent sources from the reworking of distinct crustal fragments, mostly at the South, Paleoproterozoics and at North Mesoproterozoics.
\end{abstract}

Keywords: granitoid Rocks, geochronology, Paraguai Folded Belt, Cuiabá Group.

1 - Universidade Estadual Paulista, IGCE/UNESP, Departamento de Petrologia e Metalogenia, Rio Claro (SP), Brasil.

E-mail: mgodoy@rc.unesp.br

2 - UFMT/ICET, Departamento de Recursos Minerais, Cuiabá (MT), Brasil. E-mail: aguapei@yahoo.com

3 - Universidade Estadual Paulista, IGCE/UNESP, Programa de Pós-Graduação em Geociências, Rio Claro (SP), Brasil.

E-mail: manzanojc@gmail.com

4 - UFBA, Instituto de Ciências Ambientais e Desenvolvimento Sustentável, Barreiras (BA), Brasil.

E-mail: larissamarquesba@gmail.com

5 - Companhia Matogrossense de Mineração - METAMAT, Cuiabá (MT), Brasil. E-mail: jesuesilva@yahoo.com.br

6 - Universidade do Estado de Mato Grosso, UFMT/ ICSA, Departamento de Geografia, Cáceres (MT), Brasil. 
INTRODUÇÃO A Província Granitóide Neoproterozóica do sudeste matogrossense está relacionada à evolução da Faixa de Dobramento Paraguai situada no limite sudeste do Cráton Amazônico. A Província Granitóide Matogrossense é constituída por sete corpos ígneos intrusivos em rochas epimetamórficas do Grupo Cuiabá e, pelas suas características genéticas e evolutivas, foram reunidas em dois grandes grupos e/ou eventos magmáticos denominados de suítes magmáticas sul e norte (Godoy et al. 2004, 2007) e Manzano (2009).

A suíte magmática sul é constituída por rochas granitóides que afloram no Estado de Mato Grosso do Sul e apresentam feições geológicas que permitem agrupá-los pelas suas características geoquímicas em dois conjuntos menores: os da parte setentrional (Sonora e Coxim) e os da parte meridional (Rio Negro e Taboco) (Godoy et al. 2005a e 2005b). Esses corpos ocorrem na forma de intrusões alongadas e alinhadas segundo direção NNE-SSW imposta pela orientação da "Zona de Cisalhamento Sul Matogrossense" e afloram nos contrafortes erosivos da Serra de Maracajú, no contato entre as rochas do Grupo Cuiabá e as da Formação Furnas, além de apresentarem-se parcialmente recobertos pelos sedimentos recentes da Bacia do Pantanal.

A suíte magmática norte é composta pelas rochas dos granitóides que ocorrem na forma de intrusões de dimensões batolíticas que afloram no Estado do Mato Grosso e são denominadas de oeste para leste de São Vicente, Lajinha e Araguaiana. O primeiro está alojado na região da inflexão das rochas do Grupo Cuiabá onde a direção das superfícies planares muda de direção proveniente da região sul de NNE-SSW para ENE-WSW, pela imposição do "Lineamento de Rondonópolis". Os demais granitóides ocorrem no extremo leste da faixa, controlados com a direção aproximada $\mathrm{N}-\mathrm{S}$, imposta pela estruturação das rochas metassedimentares, sendo que estes se encontram parcialmente recobertos pelos sedimentos recentes da Bacia Sedimentar do Araguaia.

$\mathrm{Na}$ área de ocorrências das duas suítes, Faixa de Dobramento Paraguai é constituída por rochas metassedimentares em fácies xisto-verde, zona da biotita, por filitos, metarritmitos e secundariamente metarenitos, metarcóseos e metaconglomerados do Grupo Cuiabá. Nas proximidades do contato com os corpos magmáticos observam-se paragêneses de metamorfismo de contato nas fácies albita a hornblenda hornfels (Godoy et al. 2007). As evidências de metamorfismo de contato nestas rochas encontram-se parcialmente preservadas, quando não há superposição das deformações miloníticas, que impõem novas feições estruturais e retrometamórficas ou quando não se encontram parcialmente recobertas pelas unidades recentes.

As ocorrências de rochas granitóides da Faixa de Dobramento Paraguai foram descritas inicialmente nos projetos governamentais do Radambrasil. Os granitóides da suíte magmática sul foram identificados nas Folhas SE. 21 Corumbá (Del'Arco et al. 1982), SF. 21 Campo Grande (Araújo et al. 1982), Folha Corumbá (Schobbenhaus Filho \& Oliva 1979), Projeto Bodoquena (Corrêa et al. 1976) e recentemente pela CPRM
(Lacerda Filho et al. 2006) no Mapa Geológico e de Recursos Minerais do Estado do Mato Grosso do Sul.

Os granitóides da parte norte da província encontram-se identificados nas Folhas SD. 21 Cuiabá (Barros et al. 1982) e SD. 22 Goiás (Drago et al. 1981), Projeto Coxipó (Luz et al. 1980) e recentemente pela CPRM (Lacerda Filho et al. 2004) no Mapa Geológico e de Recursos Minerais do Estado do Mato Grosso.

No entanto, embora esta província magmática neoproterozóica represente um importante registro da evolução tectono-magmática sin a pós-cinemática do sudeste matogrossense, apenas recentemente, estudos desenvolvidos por (Godoy et al. (2004; 2005a; 2005b; 2007), Manzano et al. (2005; 2007a; 2007b; 2008), e Manzano 2009) abordam de maneira sistemática os aspectos petrográficos, estruturais, geoquímicos e geocronológicos destes corpos. Aliados a estes dados associam-se os trabalhos geológicos nas regiões circunvizinhas das rochas encaixantes da Faixa Paraguai, que auxiliaram na compreensão dos processos petrogenéticos e do ambiente geotectônico em que estão inseridas estas manifestações ígneas (Alvarenga \& Trompette 1994, Trompette \& Alvarenga 1998, Ruiz et al. 1999).

O principal objetivo deste trabalho é a apresentação e interpretação dos dados isotópicos obtidos por Manzano (2009) e por Pinho et al. (inédito) e para estas discussões, encontram-se referenciados os dados isotópicos parciais de Ferreira et al. (2007, 2008), além de uma breve caracterização geológica e estrutural (Godoy et al. 2007) e geoquímica Godoy et al. (2005a, 2005b e 2007) e Manzano et al. (2007b) de vital importância à compreensão destas associações magmáticas.

CONTEXTO GEOLÓGICO REGIONAL O modelo de evolução da Faixa Paraguai de idade neoproterozóica proposto inicialmente por Almeida (1968, 1985, 2006) e Almeida \& Hasui (1984), apresenta aproximadamente $1.200 \mathrm{~km}$ de comprimento constituindo uma unidade geotectônica evoluída às margens SSE do Cráton Amazônico. Esta faixa apresenta um formato convexo em direção ao antepaís e estende-se aproximadamente com direção N-S desde o Paraguai e Bolívia passando Corumbá até a região de Cuiabá, onde inflete para oeste até a região da Bacia do Bananal/Araguaia.

Na região de Barra do Garças (MT) as rochas metassedimentares apresentam uma nova inflexão estrutural para norte definindo as rochas da Faixa Araguaia, que era interpretada como continuação da Faixa Paraguai, motivo pelo qual era denominada de Faixa Paraguai-Araguaia (Almeida 1968). No entanto ela foi desmembrada em duas faixas por Almeida (1985).

O modelo de evolução da faixa proposto por Brito Neves et al. (1985) e Jones (1985), interpretam que a evolução das unidades metassedimentares da Faixa de Dobramento Paraguai ocorreu em conjunto com unidades metassedimentares expostas na Bolívia, e propuseram para a confluência, que ocorre a sul de Corumbá, a partir de um ângulo de $120^{\circ}$, um modelo de junção tríplice.

Nesta linha, Litherland et al. (1986) propôs que 
o Cráton Amazônico encontra-se limitado a leste pelos cinturões móveis marginais Paraguai e Araguaia, a sul, pela Faixa Tucavaca de idade neoproterozóica que inflete oeste a noroeste em direção a Bolívia. Segundo Alvarenga \& Trompette (1993), Trompette (1994) e Trompette \& Alvarenga (1998) interpretaram a Faixa Tucavaca como um rift abortado de uma junção tríplice, Aulacógeno Tucavaca-Chiquitos e não a um cinturão marginal, gerado pela colisão do Cráton Amazônico com o Bloco Rio Apa.

Portanto, segundo Ruiz et al. (2005) o Maciço Apa adicionado ao Cráton, corresponderia a uma massa continental contínua que serviria ao mesmo tempo como substrato e área fonte desta margem passiva continental, com a formação de bacia marginal do tipo rift e constituindo o Grupo Cuiabá com a sua continuidade física, à unidade basal da Faixa Paraguai.

Almeida (1968) distinguiu três estágios estruturais na evolução da Faixa Paraguai, separados por discordâncias e mudanças contrastantes de litologias, associados a uma zonalidade tectônica e dispostos em longas e estreitas faixas paralelas à borda do cráton. $\mathrm{O}$ estágio supostamente mais antigo, representado pelas rochas do Grupo Cuiabá é formado por rochas metamórficas na fácies xisto verde, intensamente dobradas, compostas por metapelítos, tendo na base quartzitos e metacalcários subordinados. $\mathrm{O}$ estágio médio foi definido pelas rochas diamictíticas do Grupo Jangada (Formação Puga), recoberto pelas sucessões carbonáticas do Grupo Corumbá. O estágio superior é representado pelo Grupo Alto Paraguai, com sedimentação continental em sua parte superior.

Alvarenga (1988) também apresentou estruturação da faixa de dobramentos, com base nas características tectono-metamórficas, magmáticas e estratigráficas, subdividindo-a em zona externa (ocidental, menos deformada) e zona interna (oriental, mais deformada), cujos limites foram posteriormente modificados por Alvarenga \& Trompette (1993), retomando os limites das zonas estruturais definidas por Almeida (1968).

Estes domínios foram denominados mais recentemente por Ruiz et al. (1999) como Domínio Tectônico das Coberturas de Antepaís constituído por rochas metassedimentares fortemente deformadas das formações Bauxi, Puga, Araras, Raizama e Diamantino, Domínio Tectônico Externo composto pelas mesmas unidades, mas com baixa deformação e Domínio Tectônico Interno constituído pelo Grupo Nova Xavantina, restrito à região homônima e pelo Grupo Cuiabá de maior abrangência, e constitui as encaixantes de toda a província magmática. A figura 1 mostra o mapa geológico esquemático da Faixa Paraguai e sua relação com o Cráton Amazônico.

No contexto evolutivo do magmatismo da Faixa Paraguai, Lacerda Filho et al. (2004, 2006), propuseram a divisão das rochas magmáticas tardi-tectônicas em duas suítes magmáticas: A Suíte São Vicente que é constituída pelos granitos Taboco, Rio Negro, Coxim e Sonora, ao sul e o Granito São Vicente, ao norte e a Suíte Serra Negra que engloba diversos corpos graníticos pós-tectônicos do Arco Magmático de Goiás (Pimentel et al. 1996), além do batólitos Lajinha e Araguaiana no extremo sudeste do Estado de Mato Grosso, que constituem o Granito Serra Negra definido por Pimentel \& Fuck (1987).

GEOLOGIA LOCAL Na descrição dos corpos magmáticos serão mantidos, os nomes inicialmente definidos, bem como a proposta genética e geocronológica de subdivisão da província segundo Godoy et al. (2005a, 2005b, 2007). Na figura 2 é apresentado o mapa geológico com a localização dos corpos magmáticos estudados. A denominação de Granito Taboco deve-se a Corrêa et al. (1976) que assim se referiu ao corpo de rochas graníticas pós-cinemáticas, identificado inicialmente por Beurlen (1956) in Penalva (1971) e Almeida (1954), e posteriormente descritos em Del'Arco et al. (1982), Lacerda Filho et al. (2006) e Godoy et al. (2004, 2007).

As rochas deste corpo afloram em estreita faixa na margem direita do Rio Taboco (MS) e estão alojadas em filitos do Grupo Cuiabá. Nas zonas marginais do corpo ígneo os filitos passam para biotita-andalusita hornfels porfiroblásticos e/ou micaxistos. O Granito Taboco é constituído por monzogranitos de coloração rósea, avermelhada e cinza-clara, predominando as fácies porfiríticas apresentam fenocristais de feldspato potássio imersos em matriz de granulação média, geralmente isotrópicas e apresenta para a zona marginal do corpo uma borda de resfriamento de granulação fina (Godoy et al. 2007 e Manzano 2009).

O Granito Rio Negro igualmente definido por Corrêa et al. (1976) aflora à margem direita do Rio Negro (MS) e também é descrito em Del'Arco et al. (1982), Lacerda Filho et al. (2006), Manzano et al. (2005) e Godoy et al. (2004, 2007). As rochas apresentam estruturas dominantemente isotrópicas, mas localmente verificam-se rochas fortemente cataclásticas. Neste corpo foram identificadas quatro fácies principais, representadas por monzogranitos, biotita monzogranitos, granodioritos e quartzo monzonitos de granulação grossa a média e coloração variando do esbranquiçado ao cinza-escuro, inequigranulares porfiríticas. O metamorfismo de contato, parcialmente preservado no seu entorno é caracterizado pela presença de cordierita-andalusita-biotita xistos porfiroblásticos (Godoy et al. 2007 e Manzano 2009).

A denominação de Granito Coxim também deve-se a Corrêa et al. (1976). Por sua vez, Araújo et al. (1982) descreveram este corpo como possuindo uma distribuição alongada com cerca de $70 \mathrm{~km}$ de comprimento e $1 \mathrm{~km}$ de largura, de direção aproximadamente NNE, ao longo da linha de escarpas da Serra de Maracajú (MS). Lacerda Filho et al. (2006) o caracterizaram como uma intrusão fissural pós-orogenética. As rochas deste corpo são constituídas dominantemente por sieno a monzogranitos leucocráticos de coloração avermelha$\mathrm{da}$, inequigranulares de granulação fina a grossa, mas em alguns tipos porfiríticos ocorrem fenocristais de feldspato potássio de até $5 \mathrm{~mm}$. Em geral são isotrópicos, mas termos cataclásticos estão também presentes. Localmente, como mega enclaves ocorrem granodioritos, isotrópicos, de coloração rósea cinza, textura granular e 


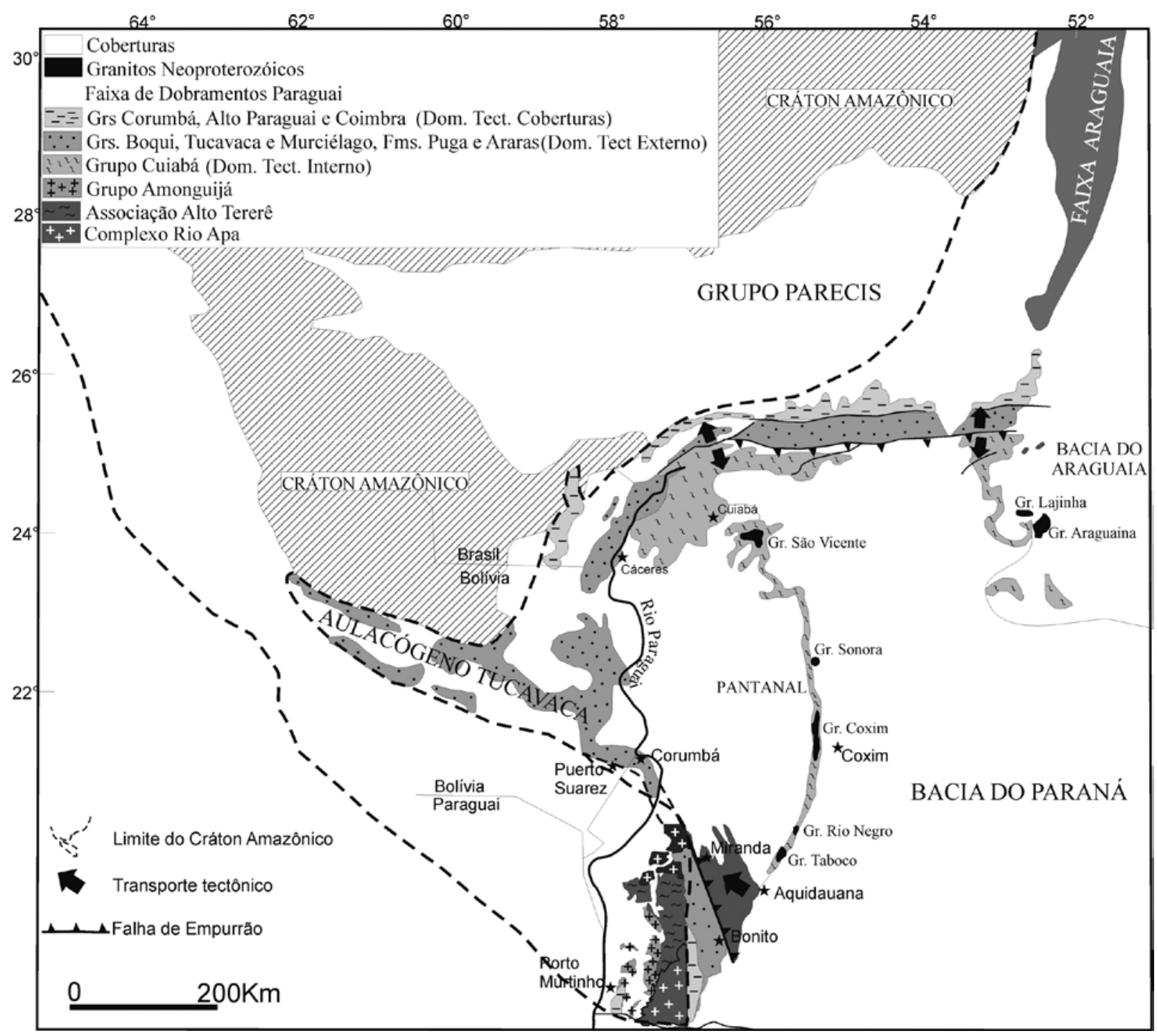

Figura 1 - Mapa geológico esquemático do Cráton Amazônico e a correlação com a Faixa Paraguai (mod. Alvarenga \& Trompette 1993, Trompette \& Alvarenga 1998, Ruiz et al. 1999).

granulação média (Godoy et al. 2007 e Manzano 2009).

O Granito Sonora (Godoy et al. 2005b) ocorre à margem direita do Rio Sonora, e os afloramentos foram expostos pelas escavações da Usina Hidroelétrica de Sonora na divisa MT/MS. Ele é constituído por sienogranitos leucocráticos de coloração vermelha, inequigranulares, granulação média a fina, isotrópicos a localmente cataclásticos.

O Batólito São Vicente foi primeiramente descrito por Almeida (1954) a leste da cidade de Cuiabá (MT) e Almeida (1968) refere-se a este granito como uma intrusão batolítica de caráter tardi cinemático. Almeida \& Montovani (1975) caracterizam a intrusão de caráter diapírico e idade relacionada ao início do metamorfismo regional do Grupo Cuiabá. Del'Arco, et al. (1982) descreveram um conjunto de rochas graníticas, suavemente orientado. Segundo Godoy et al. (2007) este batólito é constituído por biotita granitos e muscovita-biotita granitos, isotrópicos, inequigranulares, porfiríticos, podendo apresentar textura rapakivi, localmente cataclástico. Esses autores individualizaram quatro fácies texturais: a fácies equigranular grossa a porfirítica, tendo a sua maior expressão em faixa circunscrita às bordas de contato; a fácies porfirítica de matriz média a equigranular média, ocupando a zona central do corpo; a fácies equigranular fina a porfirítica, distribuída na região sudeste do batólito e a fácies pegmatítica restrita.

Observa-se em todo o maciço um grande número de diques e veios aplíticos e/ou pegmatóides de espessuras centimétricas, intenso metassomatismo com desenvolvimento (fluoritas e muscovitas) e lateralmente ao corpo ígneo, os filitos gradam localmente para andalusita-cordieritas hornfels.

Os batólitos Araguaiana e Lajinha encontramse intrusivos em filitos e afloram nas proximidades da cidade de Araguaiana (MT) e foram inicialmente descritos com estas denominações por Barros et al. (1982), Pinho et al. (1993), Sousa et al. (inédito), Ruiz et al. (1999) e Godoy et al. (2007), enquanto Pimentel \& Fuck (1987) os denominam de Granito Serra Negra pertencente a Suíte Serra Negra.

O Batólito Lajinha apresenta a forma semicir- 


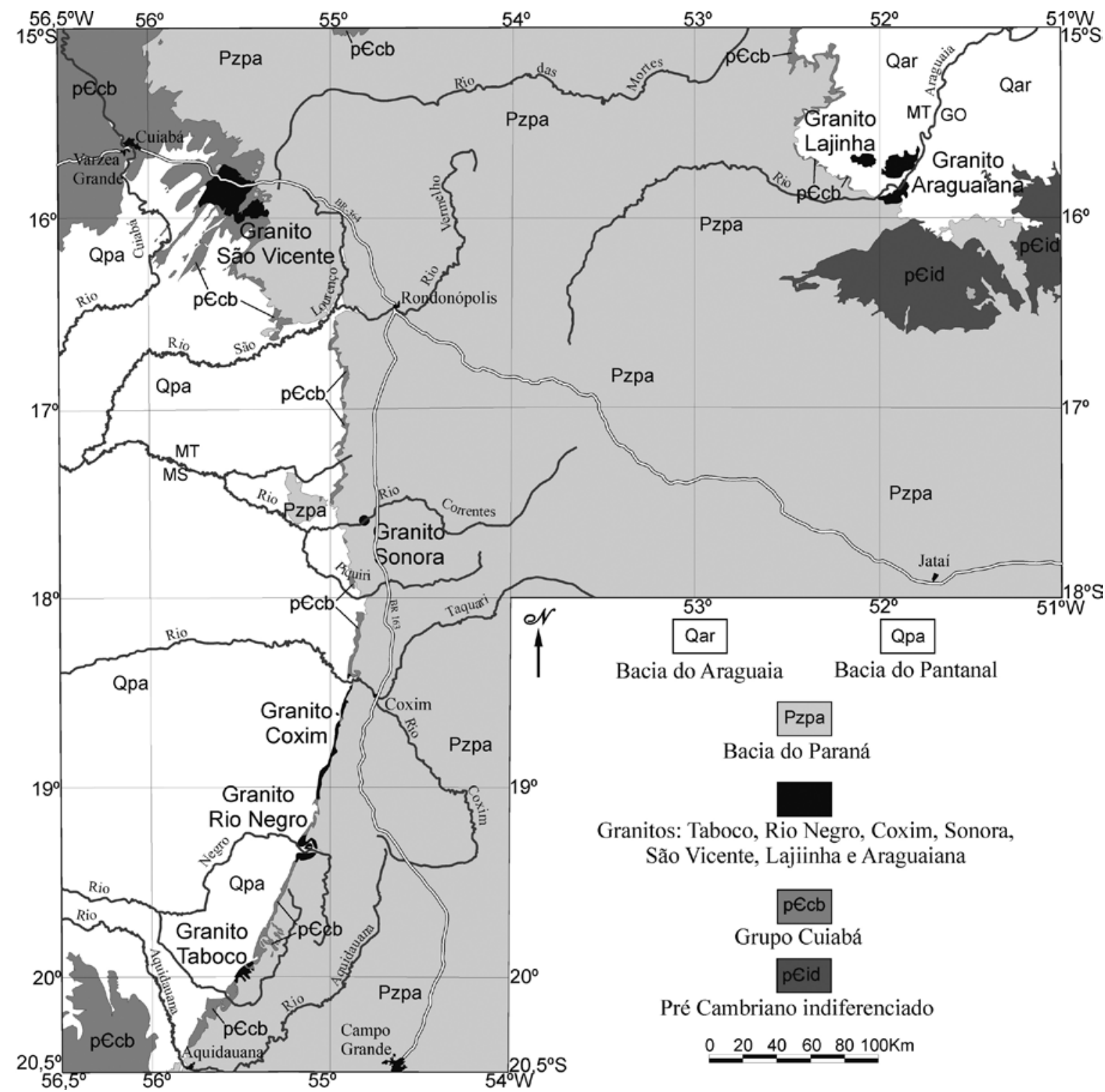

Figura 2 - Mapa geológico simplificado com a localização dos corpos granitóides neoproterozóicos (mod. Lacerda Filho et al. 2004, 2006).

cular e é constituído por sieno a monzogranitos, isotrópicos a fracamente deformados, ausência de anfibólio e variando de inequigranular a discretamente porfirítico apresentando fenocristais de feldspato potássio.

O Batólito Araguaiana apresenta rochas fortemente foliadas e cataclásticas devido à superposição da deformação de direção N-S, semelhante à deformação regional das rochas metassedimentares. É constituído por duas fácies principais de composições monzograníticas porfiríticas a megaporfiríticas, uma de coloração rósea a avermelhada e a outra cinza, com presença ou ausência de feições rapakivis. Uma terceira fácies aglutina os termos equi- inequigranulares, aplíticos e pegmatóides tardios.

CONTEXTO ESTRUTURAL O arranjo estrutural e metamórfico do Grupo Cuiabá é evidenciado pelo registro de três fases deformacionais principais na área das rochas granitóides e encontram-se descritos deta- lhadamente em Godoy et al. (2007), Manzano et al. (2007a) e Manzano (2009). Devido aos intensos processos de transposição e deformação milonítica a preservação das estruturas primárias é escassa. Apenas o acamamento gradacional reliquiar $\left(\mathrm{S}_{0}\right)$ é observado nas áreas menos deformadas, prevalecendo um bandamento tectônico imposto pelas zonas de cisalhamento.

A deformação $\mathrm{D}_{1}$ encontra-se associada ao início do processo deformacional, com formação de dobras isoclinais a recumbentes com foliação plano-axial $\mathrm{S}_{1}$ paralela a subparalela a $\mathrm{S}_{0}$, de atitude $\mathrm{N} 060 / 70 \mathrm{NW}$ e transporte provável para SE. Sincrônico, à fase $\mathrm{D}_{1}$ evidencia-se um metamorfismo regional em fácies xisto verde alcançando a zona da biotita.

$A$ fase $\mathrm{D}_{2}$ é definida por redobramentos assimétricos gerando uma clivagem ardosiana ou de crenulação $\mathrm{S}_{2}$, com atitude média de N350/30SW, com mergulhos podendo variar de baixo a médio no segmento sul da Faixa Paraguai (MS). Constitui a fase mais importante no 
rearranjo tectônico, sendo responsável pelo desenho dos dobramentos regionais, que invariavelmente são inversos ou recumbentes e associam-se às zonas de cavalgamento. $\mathrm{O}$ transporte tectônico da fase $\mathrm{D}_{2}$ é para sudeste ou sul, em direção oposta ao Cráton Amazônico. Localmente ocorrem as duas foliações $\mathrm{S}_{1 / 2}$, portanto no geral, quando paralelizadas apenas a foliação $S_{2}$ é preservada.

A granitogênese neoproterozóica associa-se a uma tectônica dúctil tardi $\mathrm{S}_{2}$ com emplacement das rochas granitóides apresentando nos hornfels o desenvolvimento de porfiroblastos controlado pela clivagem de crenulação $S_{2}$.

A fase $\mathrm{D}_{3}$ de caráter dúctil-rúptil e retrometamórfica é definida pela formação de dobras suaves a abertas (sinformais e antiformais) e sanfonadas de eixo sub-horizontal, com uma tênue clivagem sub-vertical, com plano axial de atitude $\mathrm{N} 010 / 80 \mathrm{NW}$, que evolui gradativamente e localmente para falhas direcionais, ambas paralelas ao "trend" da Faixa Paraguai definindo a Zona de Cisalhamento Sul Matogrossense. A foliação $\mathrm{S}_{3}$ é penetrativa nas zonas de cisalhamento caracterizando-se como uma foliação milonítica, com a geração de filonitos com acamamento tectônico que oblitera estruturas reliquiares. Esta foliação mostra direções que variam conforme o traçado curvilíneo do cinturão, de N para NNE e indicativo de movimentos basicamente horários no conjunto das zonas de cisalhamento. As rochas granitóides apresentam localmente, quando expostas, um caráter fracamente milonítico e/ou cataclástico nas suas bordas.

CONTEXTO LITOGEOQUíMICO Os trabalhos que tratam dos aspectos químicos destas rochas granitóides são escassos. Pinho et al. (1993) reportaram resultados para o Batólito São Vicente e Godoy et al. (2005a, 2005b, 2007) e Manzano (2009) apresentam dados geoquímicos abrangendo todo o conjunto das rochas graníticas. Estes estudos corroboraram a proposta inicial de Godoy et al. (2004) de subdivisão das rochas granitóides em dois grandes grupos e/ou eventos magmáticos.

Os granitóides da província magmática sul apresentam valores de sílica no intervalo de $68 \%$ a $78 \%$, com exceção do Granito Rio Negro que apresenta valores mais baixos, no intervalo de $60 \%$ a $68 \%$. São granitóides do Tipo I, cálcio-alcalino de alto potássio, predominantemente peraluminosos, gerados em ambiente sin- colisional de arco continental, com exceção de algumas amostras mais ricas em máficos do Granito Rio Negro, que apresentam caráter metaluminoso, e consequentemente menos diferenciado, correspondem a um ambiente pré-colisional Godoy et al. (2005a, 2005b, 2007) e Manzano (2009).

Admite-se para esse grupo de granitóides a distinção de dois conjuntos menores, com base nas características composicionais e geoquímicas, visto pelo acréscimo no nível de diferenciação dos maciços meridionais (Taboco e Rio Negro) para os setentrionais (Coxim e Sonora) com consequentemente elevação nos teores de elementos terras raras e aumento nos valores das anomalias negativas de Eu.

Para estes granitóides sin-colisionais sugere-se o seu emplacement na construção do Arco Magmático Neoproterozóico "Paraguai" a partir da fusão de material da crosta inferior heterogênea, constituindo magmas distintos e não cogenéticos e apresentando-se em níveis de fracionamento distintos (Manzano 2009).

Os granitóides da suíte magmática norte, de maneira geral rapakivíticos, apresentam valores elevados de sílica no intervalo de $68 \%$ a $77 \%$, com a maior concentração ao redor de $76 \%$ e valores acentuados de $\mathrm{Na}_{2} \mathrm{O}$ e $\mathrm{K}_{2} \mathrm{O}$, aumento acentuado nos teores de elementos terras raras e intensificação da anomalia negativa de $\mathrm{Eu}$, identificando um conjunto de rochas enriquecidas e mais diferenciadas.

São granitóides do Tipo I, cálcio-alcalino de alto potássio a shoshonítico, peraluminosos a metaluminosos, gerados em ambiente de colisão continental e/ou de descompressão pós-colisional. O Batólito Araguaiana apresenta caráter sin-colisional, formado em possíveis ambientes de arco continental e os batólitos São Vicente e Lajinha são de ambiente pós-colisionais a intraplaca (Godoy et al. 2005a, 2005b, 2007 e Manzano 2009). As rochas mais tardias dos três corpos, principalmente de caráter rapakivi, caracterizam granitos cálcio-alcalinos a alcalinos, altamente diferenciados e similares aos granitos do Tipo A de ambiente intraplaca.

Portanto, estes corpos da parte norte representam intrusões tardias distintas e não cogenéticas no ciclo magmático a partir da fusão de material da crosta inferior em ambiente final da colisão continental, associados a um ambiente final extensional da Faixa Paraguai e consequentemente a sua distinção dos granitóides do conjunto sul.

CONTEXTO GEOCRONOLÓGICO Os dados de geocronologia das rochas granitóides eram até então escassos e se restringiam às idades obtidas pelos métodos $\mathrm{K}-\mathrm{Ar}$ e $\mathrm{Rb}-\mathrm{Sr}$ e localmente U-Pb em zircão por Lacerda Filho et al. (2006). A obtenção de um maior número de idades $\mathrm{U}-\mathrm{Pb}$ e da assinatura isotópica Sm-Nd dessas rochas são de extrema importância na compreensão dos processos tectôno-magmáticos ocorridos na evolução da Faixa Paraguai.

As análises foram realizadas no Laboratório de Estudos Geocronológicos, Geodinâmicos e Ambientais, do Instituto de Geociências da Universidade de Brasília (UnB), sendo analisadas sete amostras pelos métodos $\mathrm{Sm}-\mathrm{Nd}$ e U-Pb dos respectivos corpos magmáticos que foram caracterizadas petrograficamente e geoquimicamente a partir das amostragens identificadas em Godoy et al. (2005a, 2005b, 2007). As análises das amostras da suíte magmática sul (Taboco, Rio Negro, Coxim e Sonora) encontram-se descritas em Manzano (2009) e serão apresentadas neste trabalho. As análises das rochas da suíte magmática norte encontram-se descritas em Ferreira et al. $(2007,2008)$ e somente serão utilizados os seus resultados analíticos nas discussões da evolução magmática.

Para a determinação da composição isotópica Sm-Nd utilizou-se o espectômetro de massa de ionização termal (TIMS) com multi-collector Finnigan, modelo MAT 262 utilizando os procedimentos descritos 
em Gioia \& Pimentel (2000). Para a determinação de idades U-Pb em zircões utilizou-se o espectrômetro de massa com fonte de plasma multicoletores modelo Neptune acoplado a um sistema de ablasão por laser Nd: YAG $213 \mathrm{~nm}$ (LA-MC-ICPMS).

Os dados isotópicos $\mathrm{Sm}-\mathrm{Nd}$ e U-Pb em zircão da suíte magmática norte (São Vicente, Lajinha e Araguaiana) foram obtidos por Pinho et al. (inédito), no Laboratório de Geologia Isotópica da Universidade do Kansas- EUA. As análises Sm-Nd foram realizadas por meio de um TIMS VG Sector Multicoletor seguindo os procedimentos descritos em Patchet \& Ruiz (1987) e as análises $\mathrm{U}-\mathrm{Pb}$ em zircão foram realizadas por meio do método convencional de diluição isotópica, utilizando o mesmo TIMS.

Dados isotópicos da suíte magmática sul As primeiras referências às idades radiométricas dos corpos graníticos são atribuídas a Schobbenhaus Filho \& Oliva (1979) e Del'Arco et al. (1982) que obtiveram para o Granito Coxim, uma isócrona $\mathrm{Rb} / \mathrm{Sr}$ de referência com as idades respectivamente de $552 \pm 31$ Ma e $570 \pm 20$ $\mathrm{Ma}$, interpretada como a idade do último evento termal sofrido pelo corpo.

Para o Granito Taboco, Araujo et al. (1982) e Del'Arco et al. (1982) obtiveram uma isócrona $\mathrm{Rb} / \mathrm{Sr}$ de referência com as idades respectivamente de $490 \pm$ $8 \mathrm{Ma}$ e $636 \pm 38 \mathrm{Ma}$. Por sua vez Lacerda Filho et al. (2006) apresentaram para o Granito Taboco idade U-Pb em zircão de $546 \pm 3$ Ma. Para o Granito Rio Negro Del'Arco et al. (1982) obtiveram uma isócrona $\mathrm{Rb} / \mathrm{Sr}$ de referência com a idade de $490 \pm 8 \mathrm{Ma}$. Os dados isotópicos $\mathrm{Sm}-\mathrm{Nd}$ e as idades $\mathrm{U}-\mathrm{Pb}$ em zircão para a suíte magmática sul evento magmático sul obtidas por Manzano (2009) encontram-se sumarizados na (Tab. 1).

Os resultados isotópicos Sm-Nd (Tab. 1) apresentam valores de $\varepsilon_{\mathrm{Nd}}$ para a idade de cristalização da rocha de $\varepsilon_{\mathrm{Nd}}{ }^{(0,54 \mathrm{Ga})}$, variando entre valores negativos de $(-7,4$ a $-5,9)$, o que sugerem para a fonte magmática a participação de material crustal na formação do magma ou de uma fonte com forte participação de rochas mais diferenciadas e evoluídas.

As idades modelo $\mathrm{T}_{\mathrm{DM}}$, segundo o modelo de DePaolo (1980), são para os maciços Taboco de 1,97 $\mathrm{Ga}$, para o Rio Negro de 1,59 Ga e para o Coxim de 1,74 $\mathrm{Ga}$, mostram um grande intervalo de tempo (380 Ma) entre os corpos nas proveniências das fontes magmáticas. Essas idades modelo sugerem que os magmas que deram origem a esses granitóides foram provenientes de fontes distintas e independentes, que certamente envolveram retrabalhamento de fragmentos crustais formados dominantemente no paleoproterozóico. Deve-se também considerar a possível alternativa que estas idades modelo obtidas podem ser resultado de misturas de fontes de idades distintas.

Os resultados analíticos das amostras submetidas à determinação isotópica pelo método $\mathrm{U}-\mathrm{Pb}$ em monocristais de zircão são apresentadas na tabela 1 . O Granito Taboco tem idade de $540 \pm 4.7 \mathrm{Ma}$, o Granito Rio Negro a idade de $547 \pm 4.9 \mathrm{Ma}$, o Granito Coxim a idade de $540 \pm 3.6$ Ma e o Granito Sonora a idade de $548 \pm 5.9$ Ma. Essas idades são interpretadas como a idade de cristalização desses corpos magmáticos. Os diagramas concórdia para o granitos Taboco, Rio Negro, Coxim e Sonora são mostrados nas figuras 3a-d.

As idades U-Pb em zircões dos corpos graníticos da suíte magmática sul se superpõem no intervalo dos erros analíticos sugerindo que estes corpos atingiram o estágio final de cristalização aproximadamente no mesmo período, mas quimicamente de magmas de fontes distintas e independentes e que sofreram processos evolutivos distintos.

$\mathrm{O}$ emplacement magmático apresentando as formas alongadas e fissurais e uma disposição lateralmente dos maciços, resulta do controle final imposto ao longo da "Zona de Cisalhamento Sul Matogrossense", de direção geral N-S. A idade Rb-Sr de 490 Ma obtida por Del'Arco et al. (1982) para os granito Taboco e Rio Negro representaria o registro final superimposto do período de resfriamento metamórfico regional ou efeito da zona de cisalhamento.

Dados isotópicos da suíte magmática norte As primeiras referências às idades radiométricas das rochas graníticas da suíte magmática norte são atribuídas ao Batólito São Vicente onde, através do método do K-Ar em biotitas, Amaral et al. (1966) obteve a idade de $490 \pm$ $8 \mathrm{Ma}$ e Hasui \& Almeida (1970) idade de $504 \pm 12 \mathrm{Ma}$. Posteriormente, Almeida \& Mantovani (1975) apresentaram uma isócrona $\mathrm{Rb}-\mathrm{Sr}$ de referência que forneceu idade de $483 \pm 8 \mathrm{Ma}$. Essas idades foram interpretadas como a idade de cristalização desse corpo ígneo.

Tabela 1 - Resultados isotópicos Sm-Nd e idades U-Pb em zircão para os corpos Taboco, Rio Negro, Coxim e Sonora (Manzano (2009).

\begin{tabular}{|c|c|c|c|c|c|c|c|c|c|}
\hline Batólito & $\begin{array}{c}\mathrm{Sm} \\
(\mathrm{ppm})\end{array}$ & $\begin{array}{c}\mathrm{Nd} \\
(\mathrm{ppm})\end{array}$ & $\begin{array}{l}{ }^{147} \mathrm{Sm} / \\
{ }^{144} \mathrm{Nd}\end{array}$ & $\begin{array}{c}{ }^{143} \mathrm{Nd} /{ }^{144} \mathrm{Nd} \\
\pm 2 \mathrm{E}\end{array}$ & $\varepsilon_{\mathrm{Nd}}^{(0)}$ & $\begin{array}{l}\mathrm{T}_{\mathrm{DM}} \\
(\mathrm{Ga})\end{array}$ & $\begin{array}{c}{ }^{87} \mathrm{Sr} /{ }^{86} \mathrm{Sr} \\
\pm 2 \mathrm{SE}\end{array}$ & $\begin{array}{l}\mathrm{U} / \mathrm{Pb} \\
(\mathrm{Ma})\end{array}$ & $\varepsilon_{\mathrm{Nd}}^{(540 \mathrm{Ma})}$ \\
\hline Taboco & 5,59 & 24,63 & 0,1372 & $0,512048+/-7$ & $-11,5$ & 1,97 & $0,728061+/-1$ & 540 & $-7,4$ \\
\hline Rio Negro & 3,64 & 19,92 & 0,1104 & $0,511953+/-6$ & $-13,4$ & 1,59 & $0,715455+/-2$ & 547 & $-7,4$ \\
\hline Coxim & 6,92 & 31,5 & 0,1327 & $0,512109+/-6$ & $-10,3$ & 1,74 & $0,722408+/-1$ & 540 & $-5,9$ \\
\hline Sonora & 5,47 & 19,41 & 0,1703 & $0,512184+/-6$ & - & - & - & 548 & $-7,0$ \\
\hline
\end{tabular}



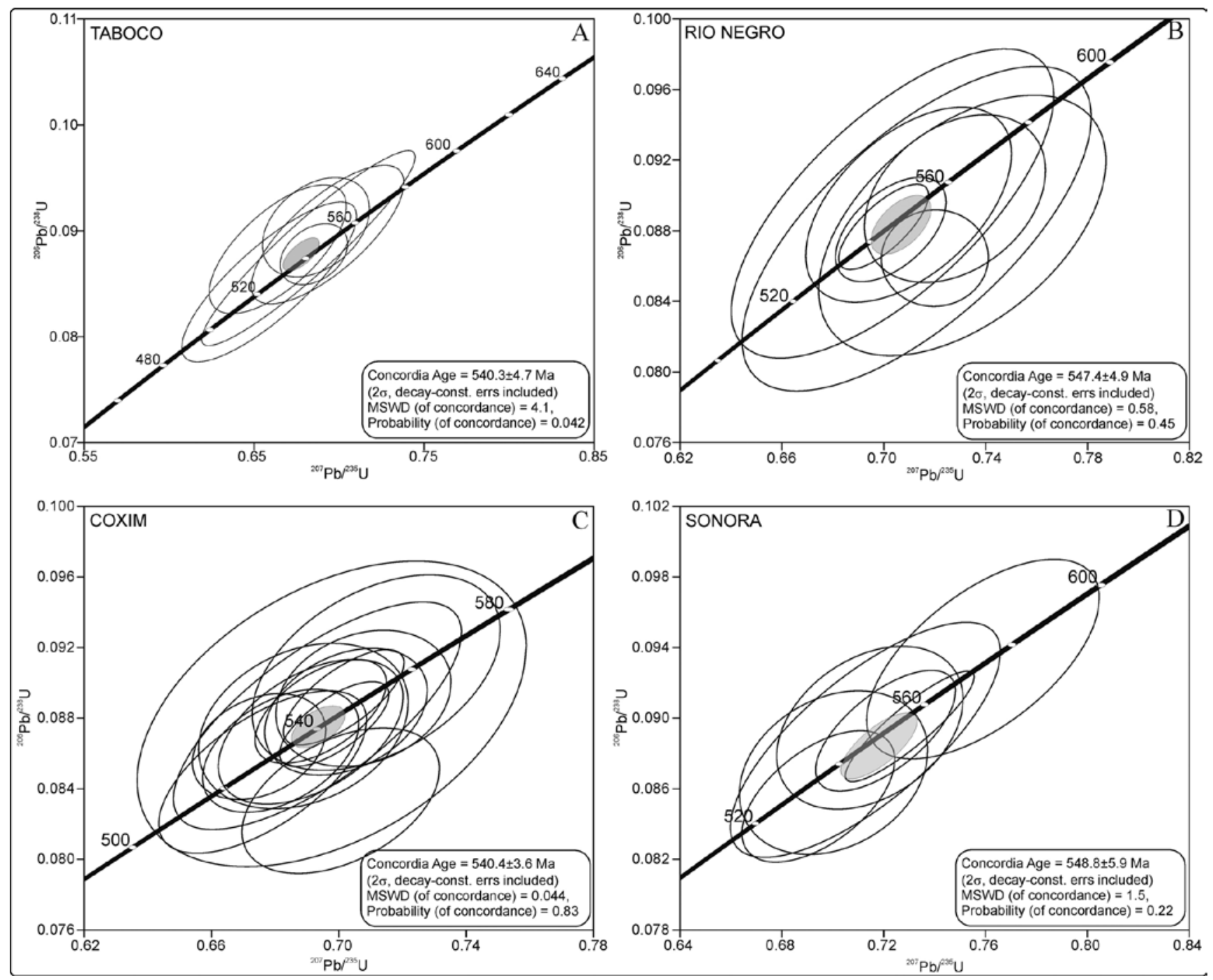

Figura 3 - Diagramas concórdias das idades isotópicas U-Pb: a) Granito Taboco, b) Granito Rio Negro, c) Granito Coxim e d) Granito Sonora (Manzano (2009).

Hasui \& Almeida (1970) apresentaram duas idades radiométricas para as rochas do Batólito Araguaiana, uma datação pelo método $\mathrm{K} / \mathrm{Ar}$ realizada em biotita que indicou a idade mínima de $488 \pm 15$ Ma e uma isócrona $\mathrm{Rb} / \mathrm{Sr}$ pelo método convencional que apresentou idade de $500 \pm 15$ Ma. Pimentel \& Fuck (1987) obtiveram pelo método convencional, isócronas $\mathrm{Rb} / \mathrm{Sr}$ com idade de 524 \pm 16 Ma para as rochas do Batólito Araguaiana, e para as rochas do Batólito Lajinha idade de $476 \pm 14$ MA. Os dados $\mathrm{Sm}-\mathrm{Nd}$ e U-Pb obtidos por Pinho et al. (inéditos) são apresentados na tabela 2 .

Os resultados isotópicos $\mathrm{Sm}-\mathrm{Nd}$ (Tab. 2) apresentam valores de $\varepsilon_{\mathrm{Nd}}$ para a idade de cristalização da rocha de $\varepsilon_{\mathrm{Nd}}^{(0,5 \mathrm{Ga})}$, variando entre valores negativos de $(-2,86$ a $-5,87)$. Estes valores também sugerem a importante participação de material crustal na formação do magma, também reforçados pelos valores característicos de crosta continental obtidos nos valores de $147_{\mathrm{Sm}} / 144_{\mathrm{Nd}}$.

As idades modelo $\mathrm{T}_{\mathrm{DM}}$, segundo o modelo de DePaolo (1980), são para os batólitos São Vicente de 1,165 Ma, para o Lajinha de 1,508 Ma e para o Araguaiana de 1,375 Ma (Tab. 2).
$\mathrm{O}$ intervalo de tempo entre as idades $\mathrm{T}_{\mathrm{DM}}$ de (343 Ma) caracteriza contribuições de fontes magmáticas distintas principalmente para o Batólito São Vicente $(1,1 \mathrm{Ma})$ em relação ao conjunto Lajinha e Araguaiana (1,5 e 1,3 Ma). Essas idades modelo sugerem que os magmas que deram origem a esses granitóides foram provenientes de fontes distintas e independentes, e que certamente envolveram retrabalhamento de fragmentos crustais mais jovens, formados predominantemente no Meso a Neoproterozóicos, quando comparadas às idades modelo dos granitos da província magmática do sul. Deve-se também considerar a possível alternativa que estas idades modelo obtidas podem ser resultado de misturas de fontes de idades distintas.

As idades obtidas pelo método U-Pb convencional em monocristais de zircões são apresentados na tabela 2. Os diagramas concórdia definido pelos cristais de zircão analisados são apresentados na figuras $4 \mathrm{a}-\mathrm{c}$. O Batólito São Vicente forneceu idade de $504 \pm 8.9 \mathrm{Ma}$, para o Batólito Lajinha foi obtida a idade de 505,4 $\pm 4.1 \mathrm{Ma}$ e para o Batólito Araguaiana idade de 509,4 $\pm 2.2 \mathrm{Ma}$.

O curto intervalo de tempo aproximadamente 
Tabela 2 - Resultados isotópicos Sm-Nd e idades U-Pb em zircão para os corpos São Vicente, Lajinha e Araguaiana (Pinho et al. inéditos).

\begin{tabular}{|c|c|c|c|c|c|c|c|c|}
\hline Batólito & $\begin{array}{c}\mathrm{Sm} \\
(\mathrm{ppm})\end{array}$ & $\begin{array}{c}\mathrm{Nd} \\
(\mathrm{ppm}) \\
\end{array}$ & $\begin{array}{l}{ }^{147} \mathrm{Sm} / \\
{ }^{144} \mathrm{Nd}\end{array}$ & $\begin{array}{c}143_{\mathrm{Sm}} / \\
144_{\mathrm{Nd}} \\
\end{array}$ & $\varepsilon_{\mathrm{Nd}}^{(0)}$ & $\begin{array}{l}\mathrm{T}_{\mathrm{DM}} \\
(\mathrm{Ga}) \\
\end{array}$ & $\begin{array}{l}\mathrm{U} / \mathrm{Pb} \\
(\mathrm{Ma}) \\
\end{array}$ & $\varepsilon_{\mathrm{Nd}}^{(0,5 \mathrm{Ga})}$ \\
\hline São Vicente & 3.21 & 19.4 & 0.1003 & 0.512257 & -9.07 & 1,165 & 504 & -2.86 \\
\hline Lajinha & 18.29 & 96.31 & 0.1148 & 0.5120767 & -11.3 & 1,508 & 505,4 & -5.87 \\
\hline Araguaiana & 8.45 & 49.67 & 0.1029 & 0.5120729 & -11.7 & 1,375 & 509,4 & -5.47 \\
\hline
\end{tabular}
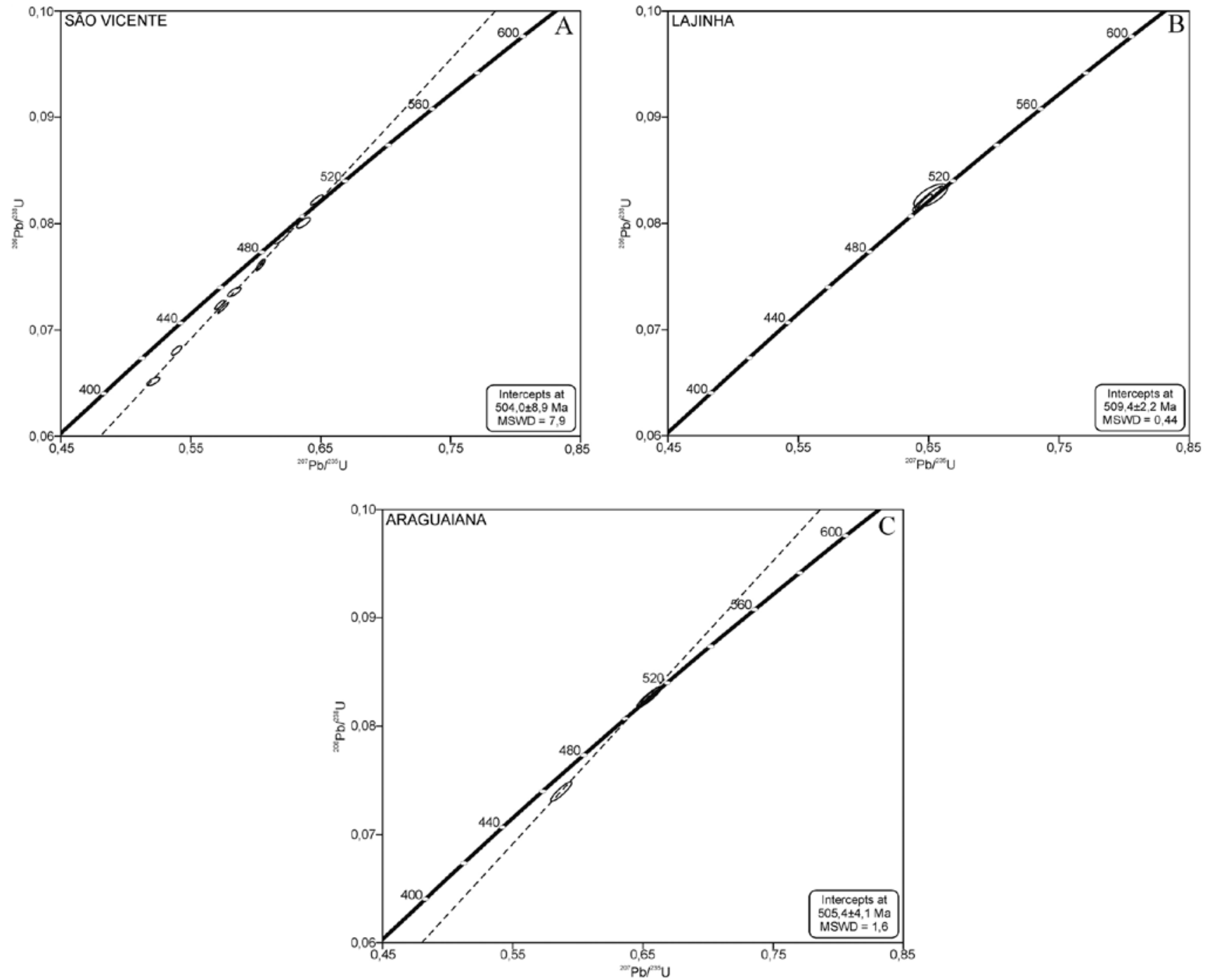

Figura 4 - Diagramas concórdias das idades isotópicas U-Pb: a) Granito São Vicente, b) Granito Lajinha e c) Granito Araguaiana (Pinho et al. inéditos).

de $( \pm 5 \mathrm{Ma})$ existente entre a cristalização destes corpos graníticos evidencia que os corpos da suíte magmática norte são contemporâneos, mas distintos e independentes e atingiram o estágio final de consolidação aproximadamente no mesmo período e são mais jovens que os corpos da suíte sul.

O emplacement magmático dos corpos da suíte norte é mais tardio associados à finalização do proces- so colisional da orogênese neoproterozóica da Faixa de Dobramento Paraguai, e que se deu a partir do retrabalhamento de fragmentos crustais mais jovens meso a neoproterozóicos, com alinhamento dos corpos, a partir da inflexão da faixa de dobramento para $\mathrm{W}$, com direção geral imposta pelo lineamento E-W.

Portanto, sugere-se que a partir do espessamento litosférico, gradualmente ampliado pelos me- 
canismos de acresção vertical (acresção plutônica) e encurtamento orogênico em um possível ambiente final extensional, conduziu ao evento final deste estágio orogênico, caracterizado pela geração e colocação das grandes massas graníticas (batólitos), os granitos tardi a pós-tectônicos rapakivíticos da província, resultando no último evento orogenético acrescionário da faixa.

EVOLUÇÃO DAS ROCHAS GRANITÓIDES Inicialmente, para a compreensão do arranjo geotectônico do magmatismo neoproterozóico na Faixa de Dobramento Paraguai, temos que considerar a geometria atual deste cinturão metamórfico, a sua origem e instalação, bem como a sua evolução tectônica e metamórfica. Inicialmente, pela linearidade e zonalidade das rochas dispostas ao longo da faixa de dobramento, sugerem-se a sua construção, inicialmente a partir de um substrato paleo a mesoproterozóico, a separação inicial do paleocontinente e instalação de uma bacia marginal do tipo rift no neoproterozóico, bordejando o Cráton Amazônico.

A continuidade física e a similaridade metamórfica e estrutural do Grupo Cuiabá, como unidade basal e com distribuição ao longo de toda borda leste da faixa de dobramento, reforçam a hipótese de uma massa continental contínua que formaria o substrato e área fonte desta margem passiva continental e a partir de um transporte de massa de SE para NW, a instalação do evento colisional e a construção da Faixa de Dobramento Paraguai, sugerido no modelo de evolução esquemático representados na figura 5 .

As deformações progressivas $\mathrm{D}_{1 / 2}$ são responsáveis pelo desenho dos dobramentos regionais na faixa de dobramento, que invariavelmente são inversos ou recumbentes e associam-se às zonas de cavalgamento com transporte de NW para SE em direção oposta ao Cráton Amazônico.

A granitogênese neoproterozóica associa-se a uma tectônica dúctil tardi $\mathrm{D}_{2}$ com emplacement das rochas ígneas e a geração de hornfels com porfiroblastos controlados pelos planos de foliação $S_{n+2}$. Como evento deformacional final instala-se uma tectônica dúctilrúptil e retrometamórfica, a fase $\mathrm{D}_{3}$, com formação de dobras suaves a abertas (sinformais e antiformais) e sanfonadas de eixo sub-horizontal, com uma tênue clivagem sub-vertical e que evoluem gradativamente e localmente para falhas direcionais, ambas com direções que variam conforme o traçado curvilíneo do cinturão, de N para NNE.

A província granitóide é identificada pelos sete corpos magmáticos e pelas suas características apresentadas mostram-se distintos e independentes, gerados a partir da fusão de uma crosta continental e marcada por dois pulsos magmáticos separados por cerca de aproximadamente $30 \mathrm{Ma}$.

Os maciços do agrupamento sul são mais antigos e gerados em ambientes sin- colisional de arco continental, e atingem a sua consolidação aproximadamente no mesmo período, com idade em torno de $540 \mathrm{Ma}$, e certamente envolveram o retrabalhamento de fragmentos crustais formados dominantemente no

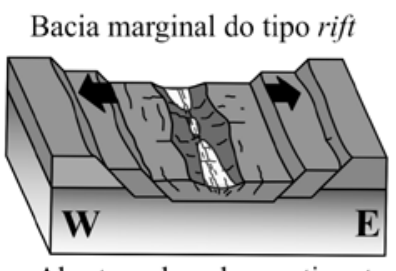

Abertura de paleocontinente

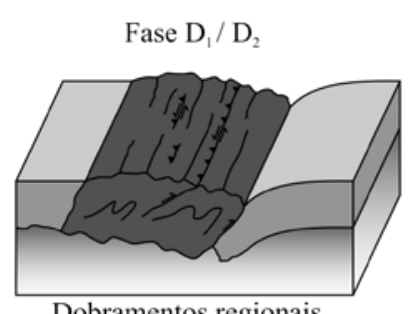

Dobramentos regionais

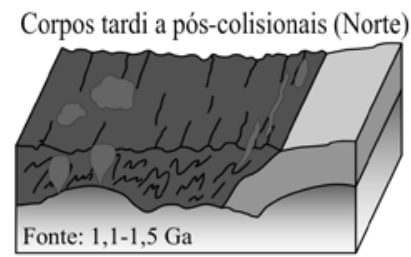

Regime extensional

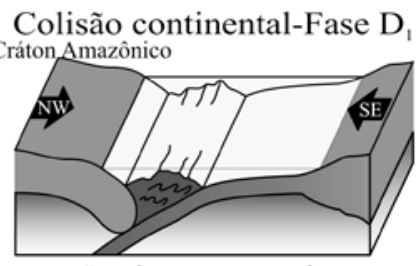

Regime compressivo
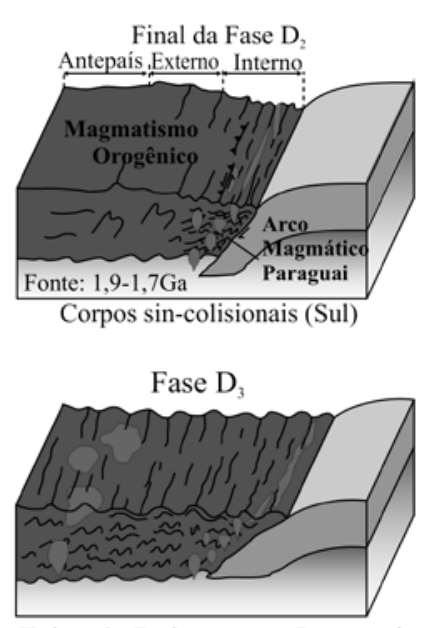

Faixa de Dobramento Paraguai
Figura 5 - Esquema da evolução Faixa Dobramento Paraguai e da Província Granitóide Matogrossense.

paleoproterozóico. As formas alongadas e fissurais dos corpos da suíte magmática sul resultaram do controle final imposto ao longo da zona de cisalhamento de direção geral N-S.

Durante o intervalo de $30 \mathrm{Ma}$ entre o alojamento dos corpos graníticos do sul e do norte, intensificou-se o espessamento crustal, gradualmente ampliado pelos mecanismos de acresção plutônica e encurtamento orogênico, conduzindo ao evento final deste estágio orogênico, caracterizado pela geração e colocação destas grandes massas batolíticas da suíte magmática norte.

As rochas destes batólitos são de natureza rapakivíticas e mais jovens, geradas em ambientes tardi a pós-colisional ou de descompressão associadas à finalização do processo colisional da orogênese neoproterozóica e atingem a sua consolidação aproximadamente no mesmo período, em torno de 510 Ma e certamente envolveram retrabalhamento de fragmentos crustais formados no Meso a Neoproterozóicos. Portanto este magmatismo seria gerado em um possível ambiente final extensional, identificado na parte norte da província, constituindo o último evento orogenético acrescionário da Faixa de Dobramento Paraguai.

CONCLUSÕES A Província Granitóide Matogrossense de idade Neoproterozóica encontra-se relacionada à evolução das rochas da Faixa de Dobramento Paraguai e ocorre no limite sudeste do Cráton Amazônico. É constituída por sete corpos ígneos distintos, intrusivos em rochas epimetamórficas do Grupo Cuiabá e constituindo duas suítes magmáticas, a do sul e do norte, 
separadas no tempo por $30 \mathrm{Ma}$.

Os granitóides do evento magmático do sul são mais antigos e ocorrem na forma de intrusões fissurais, alongadas e alinhadas na direção NNE-SSW no estado de Mato Grosso do Sul. São granitóides gerados em ambientes sin- colisional de arco continental, constituindo magmas distintos e não cogenéticos na construção do Arco Magmático Neoproterozóico "Paraguai". Os valores de $\varepsilon_{\mathrm{Nd}}{ }^{(0,54 \mathrm{Ga})}$ são negativos e as idades mode$\operatorname{los} \mathrm{T}_{\mathrm{DM}}$ apresentadas entre $(1,97 \mathrm{a}$ 1,59 Ga), sugerem a formação dos magmas a partir do retrabalhamento de fragmentos dominantemente de crosta continental paleoproterozóica. A idade de cristalização para o Maciço Taboco é de $540 \pm 4.7 \mathrm{Ma}$, para o Maciço Rio Negro é de $547 \pm 4.9 \mathrm{Ma}$, para o Maciço Coxim é de $540 \pm 3.6$ Ma e para o Maciço Sonora é de $548 \pm 5.9$ Ma.

Os granitóides do evento magmático norte são mais jovens e ocorrem na forma de intrusões batolíticas rapakivíticas dispostas segundo direção ENE-WSW no Estado do Mato Grosso. São granitóides distintos e independentes gerados em ambientes tardi a pós-colisional ou de descompressão durante a finalização do processo colisional. Os valores $\varepsilon_{\mathrm{Nd}}{ }^{(0,50 \mathrm{Ga})}$ são negativos e as idades modelos $\mathrm{T}_{\mathrm{DM}}$ apresentadas entre (1,165 a 1,59 $\mathrm{Ga}$ ), sugerem a geração de magmas a partir do retrabalhamento de fragmentos dominantemente de crosta continental meso a neoproterozóica. A idade de cristalização para o batólito São Vicente é de $504 \pm 8.9 \mathrm{Ma}$, para o Lajinha é de 505,4 \pm 4.1 Ma e para o Araguaiana é de 509,4 $\pm 2.2 \mathrm{Ma}$.

A Província Granitóide Matogrossense é marcada por dois pulsos magmáticos entre os agrupamentos do sul e do norte, separados por cerca de $40 \mathrm{Ma}$. A sua evolução ocorre a partir da separação inicial do paleocontinente e instalação de uma bacia marginal do tipo rift bordejando o Cráton Amazônico, sobre um substrato dominantemente Paleo e Neoproterozóico, e a partir de um evento colisional, instala-se o Cinturão Acrescionário Paraguai.

Consequentemente a partir do espessamento litosférico, gradualmente ampliado pelos mecanismos de encurtamento orogênico, registrado pelas fases deformacionais $\mathrm{D}_{1 / 2}$ e de acresção vertical plutônica pelo emplacement dos granitóides sin-colisionais do evento magmático sul em aproximadamente $540 \mathrm{Ma}$, conduz a um final do evento colisional para um possível ambiente final extensional com a geração e colocação das grandes massas graníticas, os granitóides tardi a pós-tectônicos rapakivíticos do evento magmático norte em aproximadamente 510 Ma, resultando no último evento orogenético acrescionário da Faixa de Dobramento Paraguai.

Agradecimentos Ao apoio da FAPESP proc. $\mathrm{n}^{\circ}$ 05/60371-6 e ao CNPq proc. $\mathrm{n}^{\circ}$ 301302/2006-5.

\section{Referências}

Almeida F.F.M. de. 1954. Geologia do centro-leste Matogrossense. Boletim da Divisão de Geologia e Mineração 150, $97 \mathrm{p}$.

Almeida F.F.M. de. 1968. Evolução tectônica do Centro-Oeste Brasileiro no Proterozóico superior. Anais da Acad. Bras. Ciên., 40:285-296.

Almeida F.F.M. de. 1985. Alguns problemas das relações geológicas entre o Cráton Amazônico e as faixas de dobramentos marginais a leste. In: SBG, Simp. Geol. CentroOeste, 2, Atas, p. 3-14.

Almeida F.F.M. de. 2006. Geologia do Continente do SulAmericano. São Paulo, Ed. Beca, 673 p.

Almeida F.F.M. de \& Hasui Y. 1984. O Pré-Cambriano do Brasil. São Paulo, Edgard Blücher Ltda, 378 p.

Almeida F.F.M. de \& Mantovani M.S.M. 1975. Geologia e geocronologia do Granito São Vicente, Mato Grosso. Anais Acad. Bras. Ciên., 47:451-58.

Alvarenga C.J.S. de. 1988. Turbiditos e a glaciação do final do Proterozóico superior no Cinturão Paraguai. Rev. Bras. de Geoc., 18:323-327,.

Alvarenga C,J.S. de \& Trompette R. 1993. Evolução Tectônica brasiliana da Faixa Paraguai: A estruturação da região de Cuiabá. Rev. Bras. Geoc., 32(4):18-30,.

Amaral G., Cordani U.G., Kawashita K., Reynolds J.H. 1966. Potassium-argon dates of basalts from southern Brazil. Geoch. Cosmochimica Acta, 30(2):159-189.

Araújo H.J.T. de, Santos Neto A. dos, Trindade C.A.H., Pinto J.C. de A., Montalvão R.M.G. de, Dourado T.D.C.,
Palmeira R.C.B., Tassinari C.C.G. 1982. Geologia. In: MME/SG (ed.) Projeto RadamBrasil, Levantamento dos Recursos Naturais. Folha SF. 21 - Campo Grande. Rio de Janeiro, 28:23-124.

Barros A.M., Silva R.H. da, Cardoso O.R.F.A., Freire F.A., Sousa Jr. J.J., Rivetti M., Luz D.S. da, Palmeira R.C. de B., Tassinari C.C.G. 1982. Geologia. In: MME/SG (ed.) Projeto RadamBrasil, Levantamento dos Recursos Naturais. Folha SD. 21-Cuiabá. Rio de Janeiro, 26:25-192.

Brito Neves, B.B. de, Campos Neto, M.C., Cordani, U.G. 1985. Ancient "Massifs" in the Proterozoic Belts of Brazil. In: Symp. Early Middle Proterozoic Fold Belts, Ext. Abstr., v.1, p. 70-72.

Corrêa J.A., Neto C., Correia Filho F.C.L., Scislewski G., Cavallon L.A., Cerqueira N.L.S., Nogueira V.L. 1976. Projeto Bodoquena-Relatório Final. Goiânia, MME/DNPM, Convênio DNPM/CPRM.

Del'Arco J.O., Silva R.H. da, Tarapanoff I., Freire F.A., Pereira L.G.M., Souza S.L., Luz D.S. da, Palmeira R.C.B., Tassinari C.C.G. 1982. Geologia. In: MME/SG (ed.) Projeto RadamBrasil, Levantamento dos Recursos Naturais. Folha SE. 21 - Corumbá e parte da Folha SE. 20. Rio de Janeiro, 27:25-160.

DePaolo D.J. 1988. Neodymium isotope geochemistry: an introduction. Berlin, Springer-Verlag, $187 \mathrm{p}$.

Drago V.A., Pinto A.C., Montalvão R.M.G. de, Santos R.O.B., Simões M.A., Oliveira F.C., Bezerra P.E.L., Prado P., Fernandes C.A.C., Tassinari C.C.G. 1981. Geologia. In: 
MME/SG (ed.) Projeto RadamBrasil, Levantamento dos Recursos Naturais. Folha SD. 22 - Goiás. Rio de Janeiro, 25:27-300.

Ferreira C.O., Pimentel M.M., Dantas E.L., Ruiz A.S. 2007. Assinatura Isotópica Sm-Nd de Gnaisses e Granitos Pósorogênicos no Limite das Faixas Brasília e Paraguai. In: SBG, Simp. Geol. Centro Oeste, 10, Res., CD-Rom.

Ferreira C., Dantas E., Pimentel M., Buhn B., Ruiz A.S. 2008. $\mathrm{Nd}$ isotopic signature and $\mathrm{U}-\mathrm{Pb} \mathrm{LA}-\mathrm{ICPMS}$ ages of Cambrian intrusive granites in the boundaries between Brasília Belt and Paraguay Belt. In: South American Symposium Isotope Geology, 6, CD-Rom.

Gioia S.M.C.L. \& Pimentel M.M. 2000. The Sm-Nd isotopic method in the Geochronology Laboratory of the University Of Brasília. Anais Acad. Bras. Ciên., 72(2):219-245.

Godoy A.M., Ruiz A.S., Araújo-Ruiz L.M.B. de, Manzano J.C., Souza M.Z.A., Matos J.B. 2004. Caracterização Geológica dos Granitóides Brasilianos Pós-Tectônico da Faixa de Dobramentos Paraguai do Sudeste Matogrossense. In: SBG, Congr. Bras. Geol., 42, Res, CD-Rom.

Godoy A.M., Ruiz A.S., Manzano J.C., Araújo-Ruiz L.M.B. de, Souza M.Z.A., Matos J.B. 2005a. Padrão Geoquímico dos Granitóides Brasilianos da Faixa Paraguai no Estado de Mato Grosso. In: SBGq, Congr. Bras. Geoq., 10 e Simp. Geoq. Países Mercosul, 2, Porto de Galinhas, Bol., CD-Rom.

Godoy A.M., Ruiz A.S., Manzano J.C., Araújo-Ruiz L.M.B. de, Souza M.Z.A., Matos J.B. 2005b. Litogeoquímica dos Granitóides Brasilianos Pós-Tectônicos do Mato Grosso Sul. In: SBGq, Congr. Bras. Geoq., 10 e Simp. Geoq. Países Mercosul, 2, Bol., CD-Rom.

Godoy A.M., Manzano J.C., Ruiz A.S., Araujo L.M.B. de. 2007. Os Granitóides Brasilianos Pós-Tectônicos da Faixa de Dobramentos Paraguai MS e MT. Geologia USP, Série Científica, 7:29-44.

Hasui Y. \& Almeida F.F.M de. 1970. Geocronologia do centro-oeste brasileiro. Bol. Soc. Bras. Geol., 19:1-26.

Jones J.P. 1985. The southern border of the Guaporé Shield in western Brazil and Bolívia: an interpretation of its geologic evolution. Precambrian Res., 28:111-135.

Lacerda Filho J.W., Abreu Filho W., Valente C.R., Oliveira C.C., Albuquerque M.C. 2004. Geologia e Recursos Minerais do Estado de Mato Grosso. Programa Integração, Atualização e Difusão de Dados de Geologia do Brasil. Convênio CPRM/SICME-MT, MME. 235 p.

Lacerda Filho J.W., Brito R.S.C., Silva M.G., Oliveira C.C., Moreton L.C., Martins E.G., Lopes R.C., Lima T.M., Larizzatti J.H. Valente C.R. 2006. Geologia e Recursos Minerais do Estado de Mato Grosso do Sul. Programa Integração, Atualização e Difusão de Dados de Geologia do Brasil. Convênio CPRM/SICME-MS, MME, 121 p.

Litherland M., Annells R.N., Appleton J.D., Berrangé J.P., Bloomfield K., Burton C.C.J., Darbyshire D.P.F., Fletcher C.J.N., Hawkins M.P., Klinck B.A., Llanos A., Mithcell W.I., O’Connor E.A., Pitfield P.E.J., Power G.E., Webb B.C. 1986. The geology and mineral resources of the bolivian precambrian shield. British geological survey, Overseas memoir 9, $140 \mathrm{p}$.

Luz J.S., Oliveira A.M., Souza J.O., Motta J.F.M., Tanno L.C., Carmo L.S., Souza N.B. 1980. Projeto Coxipó. Goiânia,
DNPM/CPRM, Relatório Final, v.1, 136 p.

Manzano J.C. 2009. Caracterização dos Granitóides Brasilianos da Faixa de Dobramento Paraguai, MT e MS. Dissertação de Mestrado, Instituto de Geociências e Ciências Exatas, Universidade Estadual Paulista, 99 p.

Manzano J.C., Godoy A.M., Ruiz A.S., Araújo-Ruiz L.M.B. de, Sousa M.Z. de A., Matos J.B. 2005. Os Granitóides Brasilianos Pós-Tectônicos da Faixa Paraguai. In: SBG, Simp. Geol. Centro Oeste, 9, Atas, CD-Rom.

Manzano J.C., Godoy A.M., Araujo L.M.B. de, Ruiz A.S. 2007a. Controle Deformacional dos Granitóides da Faixa de Dobramentos Paraguai, MS. In: SBG, Simp. Nac. Est. Tect., IX, Natal. Bol., p. 291-293.

Manzano J.C., Godoy A.M., Ruiz A.S., Araujo L.M.B. de. 2007b. Litogeoquímica da Província Granitóide Brasiliana Pós-Tectônica da Faixa de Dobramentos Paraguai. In: SBG, Cong. Bras. Geoq., XI, Bol., CD-Rom.

Manzano J.C., Godoy A.M., Araújo L.M.B. de. 2008. Contexto Tectônico dos Granitóides Neoproterozóicos da Faixa de Dobramento Paraguai, MS e MT. Geoc., 27(4):493-507.

Patchett P.J. \& Ruiz J. 1987. Nd isotopic ages of crust formation and metamorphism in the Precambrian of eastern and southern Mexico. Contr. Miner. Petrol., 96:523-528.

Penalva F. 1971. Reconhecimento geológico da faixa précambriana na borda leste do Pantanal de Mato Grosso. Anais Acad. Bras. Ciên., 43(2):449-54.

Pimentel M.M \& Fuck R.A. 1987. Late proterozoic granitic magmatism in southwestern Goiás, Brazil. Rev. Bras. de Geoc., 17(4):415-425.

Pimentel M.M., Fuck R.A., Alvarenga C.J. 1996. PostBrasiliano (Pan-African) high-K granitic magmatism in Central Brazil: the role of Late Precambrian-early Paleozoic extension. Precambrian Research, 80:217-238.

Pinho M.A.S.B., Borges L.E.P., Pinho F.E.C., Leite J.D., Figueiredo M.H. 1993. Geoquímica dos elementos Terras Raras em granitóides ocorrentes no Estado de Mato Grosso. In: SBG, Simp. Geol. Nord., 15, Atas, p.195-208.

Ruiz A.S., Sousa M.Z.A., Ruiz L.M.B.A. 1999. A faixa de dobramentos Paraguai e os granitóides tardi-cinemáticos: uma caracterização preliminar dos granitóides Lajinha e Araguaiana no leste matogrossense. In: SBG, Simp. Geol. Amaz., 6, Anais, p. 307-10.

Ruiz A.S., Simões L.S.A., Brito-Neves B.B. 2005. Maciço Rio Apa: extremo meridional do Cráton Amazônico. In: SBG, Simp. Est. Tect.,10, Anais, p. 301-304.

Schobbenhaus Filho C. \& Oliva L.A. 1979. Carta geológica do Brasil ao milionésimo. Folha Corumbá (SE. 21). Brasília, DNPM.

Trompette R.R. 1994. Geology of Western Gondwana (2000500 Ma): Pan-African-Brasiliano Aggregation of South America and Africa. Balkema, Rotterdam, $350 \mathrm{p}$.

Trompette R. \& Alvarenga C.J.S. de. 1998. Geological evolution of the Neoproterozoic Corumba graben system (Brazil). Depositional context of the stratified Fe and Mn ores of the Jacadigo Group. Journal of South American Earth Sciences, 11(6):587-597.

Manuscrito ID 16226

Submissão em 03 de dezembro de 2009 Aceite em 12 de setembro de 2010 